\title{
Hayfields enhance colony size of the Barn Swallow Hirundo rustica in northern Italy
}

\author{
BEATRICE SICURELLA, MANUELA CAPRIOLI, ANDREA ROMANO, \\ MARIA ROMANO, DIEGO RUBOLINI, NICOLA SAINO and \\ ROBERTO AMBROSINI
}

\section{Summary}

The widespread decline of farmland birds is a major issue of biological conservation in European countries. The Barn Swallow Hirundo rustica is a flagship species for farmland bird conservation owing to its aesthetic and cultural value and to the sharp decline observed in several populations. Based on a long-term monitoring project of a population in a protected area of Northern Italy, we documented a dramatic decline of $56.6 \%$ between 1999 and 2011 , corresponding to a decrease of $6.59 \%$ each year. We also showed that colonies were on average larger in farms with livestock than those without livestock, and that colony size increased with increasing extent of hayfields within $200 \mathrm{~m}$ from the colony in farms without livestock, but not in those with livestock. Hayfield extent at greater distances did not influence population size or trend. Cessation of livestock farming therefore determined a decline in local colonies, but this decline may be buffered by an increase in hayfield extent within $200 \mathrm{~m}$ from the farm. However, variation in the ecological features of breeding sites explained only a fraction of the observed population decline, suggesting that ecological conditions during migration and wintering may be crucial in affecting population trends. Mean hatching date of first broods advanced in recent years, but less so in farms with, than without, livestock. Independently of year, mean hatching date advanced more in farms with greater extent of hayfields within $200 \mathrm{~m}$ of the colony. Reproductive success, measured as the mean number of fledged offspring per nest, declined significantly with hatching date, but was not affected by hayfield extent. Conversely, nestling quality, in terms of body mass and feather development, improved with increasing extent of hayfields around the colony, particularly in late-hatched first clutches. Our findings suggest that conservation strategies for this declining species should include both the maintenance of livestock farming and the enlargement of hayfields close to breeding colonies, particularly in farms where livestock farming has ceased.

\section{Introduction}

Diverse anthropogenic factors, including habitat alteration and climate change, currently contribute to a global decline in biodiversity (Gaston et al. 2003, Thomas et al. 2004). Agricultural intensification, which has occurred in Europe since the end of the Second World War, has entailed profound environmental alterations, such as habitat homogenisation, loss of hedgerows and ponds, increase in the use of agrochemicals, and changes in farming practices (Donald et al. 2001, 2006). As a consequence, birds breeding in farmlands are suffering sharper population declines than those inhabiting other environments in Europe (Donald et al. 2001, Murphy 2003).

Among farmland birds, the Barn Swallow Hirundo rustica is a flagship species for habitat conservation, owing to its aesthetic and cultural value, and to its popularity among people (Spina 1998). Several populations of this species are currently declining throughout Europe 
(BirdLife International (2004), PECBMS 2009), although the steepness of these declines largely differs among countries (Siriwardena et al. 1998, Engen et al. 2001, Robinson et al. 2003, BirdLife International (2004)). Data from the Pan European Common Birds Monitoring Scheme indicate an overall population decline of about $40 \%$ in the period 1990-2006, with an annual decline rate of about $1 \%$ per year (PECBMS 2009). In Northern Italy, a decrease of $53.1 \%$ since 2001, corresponding to a decline rate of $8.4 \%$ per year, much larger than that observed at continental scale, has been recently documented (Ambrosini et al. 2012), so that in the near future the Barn Swallow may become a species of conservation concern in this area. A proper knowledge of the factors affecting population dynamics of this species may therefore be pivotal to plan effective conservation strategies.

The current decline of Barn Swallow populations is believed to be the consequence of several concomitant factors. Besides agricultural intensification and habitat loss, cessation of livestock farming at nesting farms contributed to the decline of colonies (Møller 2001, Ambrosini et al. 2012). Indeed, Barn Swallows preferentially breed in farms where cattle, pigs or horses are reared (Møller 2001, Ambrosini et al. 2002), and colonies decline steeply once livestock farming ceases (Ambrosini et al. 2012). In addition, changes in farming practices often result in farm remodelling, with old cowsheds and barns replaced by modern buildings, less suitable for Barn Swallow nesting (Evans et al. 2003). Finally, similar to other long-distance migrant species, habitat loss and alteration both at the wintering grounds and along migration routes (Sanderson et al. 2006, Zwarts et al. 2009), as well as dissimilar rates of climate change between breeding and wintering quarters, may have exacerbated local population declines (Both et al. 2010, Saino et al. 2011).

The strict association between livestock farming and Barn Swallows is probably due to several concomitant factors. For example, cowsheds with livestock may provide optimal nesting sites due to warmer temperatures (Ambrosini and Saino 2010). In addition, farms with livestock are usually surrounded by a larger extent of hayfields and pastures (Møller 2001, Ambrosini et al. 2002, 2012), which are the favourite foraging habitat of Barn Swallows, probably because large flying insects, which are the preferred prey of this species, are more abundant on these than on other cultures (Evans et al. 2007, Grüebler et al. 2010, Orłowski and Karg 2011). Indeed, presence of livestock enhanced nestling quality and frequency of second clutches in Denmark (Møller 2001), and nestling survival and annual offspring output of double-brooded pairs in Switzerland (Grüebler et al. 2010). In Northern Italy, pairs breeding in cowsheds with livestock advanced laying of the first clutches and produced nestlings of better overall quality (Ambrosini et al. 2006). Earlier reproduction, in turn, should enhance fitness, because it increases the probability of rearing a second clutch and because breeding success declines through the breeding season (Turner 2006). In addition, early hatch increases lifespan and lifetime reproductive success (Saino et al. 2012).

During breeding, Barn Swallows usually forage within a very narrow range around the colony and rarely move more than $500 \mathrm{~m}$ (Møller 1994). In addition, the number of foraging individuals decreases steeply at increasing distance from the colony (Ambrosini et al. 2002). It could therefore be speculated that hayfields and pastures may be more beneficial to Barn Swallows if they are close to the breeding colony.

In the present study, taking advantage of the data collected during a long-term monitoring project in Northern Italy (Ambrosini et al. 2002, 2012), we investigated whether the extent of hayfields and their spatial distribution around farms influenced the number of pairs and population trends of Barn Swallows breeding at 87 farms censused each year between 1999 and 2011. We also aimed to investigate the causal mechanisms that link annual variation in extent of hayfields around farms and the demographic trend of colonies. We therefore analysed the annual variation in clutch and brood size and hatching date recorded in the same colonies during the annual censuses: if large hayfields are beneficial to Barn Swallow reproduction, we expect clutch and brood size to increase, and hatching date to advance in farms surrounded by larger extent of hayfields.

A large extent of hayfields around the colony may not only enhance reproductive success, but also nestling quality, in terms of e.g. growth or immune response, both of which may predict postfledging survival (Møller and Saino 2004, Turner 2006). For example, foraging sites close to the nest may reduce time spent foraging, thus reducing the risk of nestling starvation, and provide 
greater food abundance or greater abundance of high-quality prey. To investigate this hypothesis we used a large dataset on nestling phenotypic traits collected in 2001 for a previous study (Ambrosini et al. 2006), in which we recorded nestling body mass, size and feather development, which positively influence offspring survival (Turner 2006, Grüebler and Naef-Daenzer 2010), and T cell-mediated immune response, which is a fundamental component of the acquired immune system (Saino et al. 1997, Christie et al. 2001). These data were re-analysed here with the specific aim of investigating the effect of the extent of hayfields around nesting sites on components of nestling phenotypic quality.

\section{Methods}

\section{Study area and census methods}

This study was carried out in the Parco Regionale Adda Sud, a wide (c.240 km²) intensively cultivated area in Northern Italy (Figure 1) where livestock farming is widespread (see Ambrosini et al. 2002 for a description of the study area).
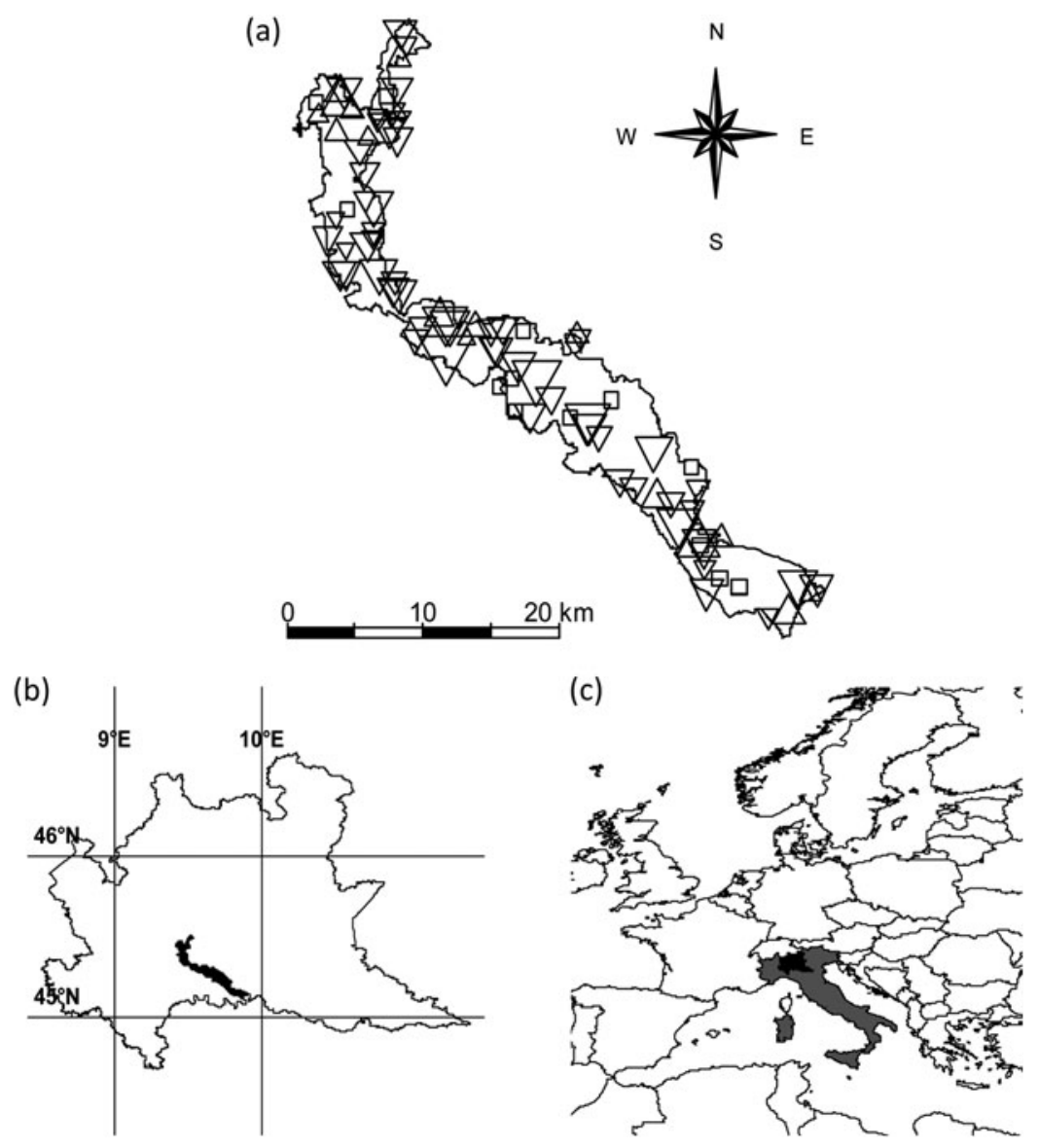

Figure 1 . (a) the study area with the 87 farms included in the study. Downward triangles indicate Barn Swallow colonies with negative demographic trends, upward triangles colonies with positive trends, squares farms with no Barn Swallow in all the years of the census. Size of triangles is proportional to the absolute value of population growth rate; (b) the study area in Lombardy; (c) Lombardy in Italy and Europe. 
In 1999 all farms in this area were censused from detailed maps (scale 1:10,000) and a sample of 107 farms was randomly chosen. In the following years the number of farms monitored varied from 96 to 160 depending on our opportunities to perform field work and to farm owners' ${ }^{\prime}$ willingness to let us visit their properties. Eighty-seven farms were censused in each year since 1999 according to a standard protocol whereby we inspected all nests in a farm every second week. All analyses of population trends were based on these 87 farms. Nest inspections started at the beginning of April, when very early first clutches are laid, and ended in mid-July, when late first clutches fledge (Ambrosini et al. 2002). Colony size was estimated as the maximum number of nests simultaneously active at a farm (Ambrosini et al. 2002).

The number of eggs and nestlings in every nest was recorded on each visit. Nestling age was estimated according to body size and plumage development (Turner 2006, see also Ambrosini and Saino 2010 for a validation of this method). Hatching date of each brood was estimated according to nestling age, and laying date was calculated assuming that Barn Swallows lay one egg per day and incubate eggs for 14 days (Møller 1994). Brood size was expressed as the number of chicks that survived at least to the age of 10 days, as mortality after age 1o days accounts for less than $5 \%$ of total nestling mortality (N. Saino unpubl. data). Thus, brood size of nests observed when nestlings were eight or nine days old and not observed again before fledging was discarded. We focused on first broods only. Since Barn Swallows may change nest between first and second breeding attempts and most birds were not individually marked, we could not directly identify second broods. To avoid including possible second broods in the study, we excluded from the analyses all the nests in which the first egg was laid after the fledging of the nest that hatched first in that colony (Ambrosini et al. 2002, 2006). During each year we obtained information on 496-1,225 first broods, although for practical reasons, not all information was available for all nests.

\section{Livestock farming and hayfield extent}

Every year, we recorded the number of cows, pigs and horses reared at each farm. These data were then summarised in a dichotomous variable accounting for livestock presence or absence. Indeed, studies conducted in the same area indicated that presence of livestock at a farm is a better predictor of Barn Swallow presence and abundance than the number of head reared (Ambrosini et al. 2002).

The extent of different crop types was also recorded on detailed (1:10,000) maps within the foraging range of Barn Swallows (400 $\mathrm{m}$ from each colony; Ambrosini et al. 2002). Maize fields and hayfields (i.e. fields where grass or alfalfa Medicago sativa are not grazed but cut to produce dry feed for livestock) represent the most common land uses in the study area (on average $44 \%$ and $35 \%$ of the area, respectively). To investigate variation in the importance of crops at different distances from the colony, we quantified the extent of hayfields within $200 \mathrm{~m}$ from the farm and between 200 and $400 \mathrm{~m}$. Hayfield extent was expressed as the proportion of the cultivated area with hayfields within each distance belt.

\section{Recording of nestling traits}

In 2001 we recorded phenotypic traits of 1,155 nestlings from 249 first broods in 57 farms. Full details of field procedures are reported in Ambrosini et al. (2006). Briefly, nests were visited daily to assess hatching date. Nestlings were individually marked and measured when they were 9-11 day old ( $23.5 \%$ were nine days old, $50.4 \%$ 1o day old, $26.1 \%$ II day old), i.e. before the physiological body mass recession that occurs before fledging (c.12 days old). We measured body mass with a spring balance (accuracy 0.1 g), right tarsus length with a calliper (accuracy $0.05 \mathrm{~mm}$ ) and innermost left rectrix length with a ruler (accuracy $0.5 \mathrm{~mm}$ ). On the same day we also injected the right wing web with a lectin (phytohemagglutinin, PHA) to do the PHA skin test, following the procedure described in Saino et al. (1997). This test is a standard method to assess T cell-mediated immune response in birds in the wild (Saino et al. 1997, Smits et al. 1999). 


\section{Statistical analyses}

Population growth rate ( $r$ parameter) was calculated as the slope of the Poisson regression (corrected for overdispersion) of the total number of breeding pairs observed in a given year on time. Variations in mean extent of hayfields around the sampled farms and in the proportion of farms with livestock during 1999-2011 were modelled with linear regression and a binomial Generalised Linear Model (GLM), respectively.

The number of breeding pairs per farm was modelled in Generalised Linear Mixed Models (GLMM) assuming a Poisson error distribution. Year (covariate), livestock farming (dichotomous variable), the proportional extent of hayfields within a distance belt ("hayfield extent" hereafter, covariate) and the two-ways interactions between these terms were entered as predictors. Hayfield extent within each distance belt was entered in separate models because these variables were strongly and positively correlated (Pearson $r=0.772$ ). Farm was entered as a random factor and year as a random slope (sensu Schielzeth and Forstmeier 2009) at the farm level in all models. All variables were centred to their mean values before the analyses. Collinearity of the predictors entered simultaneously in statistical models was carefully checked before any analysis (Variance Inflation Factor of predictors, including interaction terms $\leq 1.421$ in all cases, |Pearson $r \mid$ between predictors $\leq 0.361$ in all cases). The temporal autocorrelation of observations from the same farm was accounted for by assuming an AR(I) within-farm covariance structure in all models.

We also aimed at investigating the extent to which variation in hayfields and livestock concurred in determining population trend. To this end, we re-ran the model of colony size while excluding year from the predictors, but maintaining the auto-correlation structure. Coefficients from this model should reveal the potential impact of change in farming practice on Barn Swallow population size, irrespective of the long-term trend. Analyses of colony size were done by the $g \operatorname{lmm} P Q L$ procedure in the MASS library of R 2.8.I (R Development Core Team 2008).

Variations in mean within-farm clutch size, brood size and hatching date of first clutches were investigated in Linear Mixed Models (LMMs) assuming a Gaussian error distribution with the same random structure as the models of colony size. The same fixed predictors were entered in all models, as in models of colony size. In addition, colony size and its interaction with year were entered into models to account for potential density-dependent effects on breeding performance and their variation over time. Finally, mean hatching date and its interaction with year were entered in the models of mean clutch size and mean brood size to account for the seasonal decline in clutch and brood size (Ambrosini et al. 2006, Turner 2006). These models were fitted with the lme procedure of $\mathrm{R}$ 2.8.1.

Nestling quality was investigated in Gaussian LMMs. Presence of livestock farming at a farm (dichotomous variable), hayfield extent within $200 \mathrm{~m}$ from the colony, date at nestling measurement ("date" hereafter) and age of nestlings (covariates) were entered as fixed effects together with the interactions between date and hayfield extent and date and livestock farming. Date and age were included in the models to account for seasonal variation in nestling quality or nestling growth. Farm was entered as a random factor, date as a random slope within farm, and nest as a random factor nested within farm. Models were fitted with the lmer procedure in the lme4 package in $\mathrm{R}$ 2.8.1. Statistics are reported together with their associated standard error, unless stated otherwise.

\section{Results}

During the 13 years of the study, the population decreased by $56.6 \%$ in the 87 farms censused each year, from the 1,142 breeding pairs censused in 1999 ( $13.13 \pm 1.68$ pairs per farm on average) to the $496(5.70 \pm 0.87)$ found in 2011 (Figure 2). The annual decline rate was $6.59 \pm 1.14 \%$ (95\% Cl: $4.36 \%-8.82 \%)$.

Population declined at a constant rate, as indicated by the fact that the second and the third order polynomial terms of year were never statistically significant $\left(\left|t_{9}\right| \leq 1.259, P \geq 0.240\right)$. 


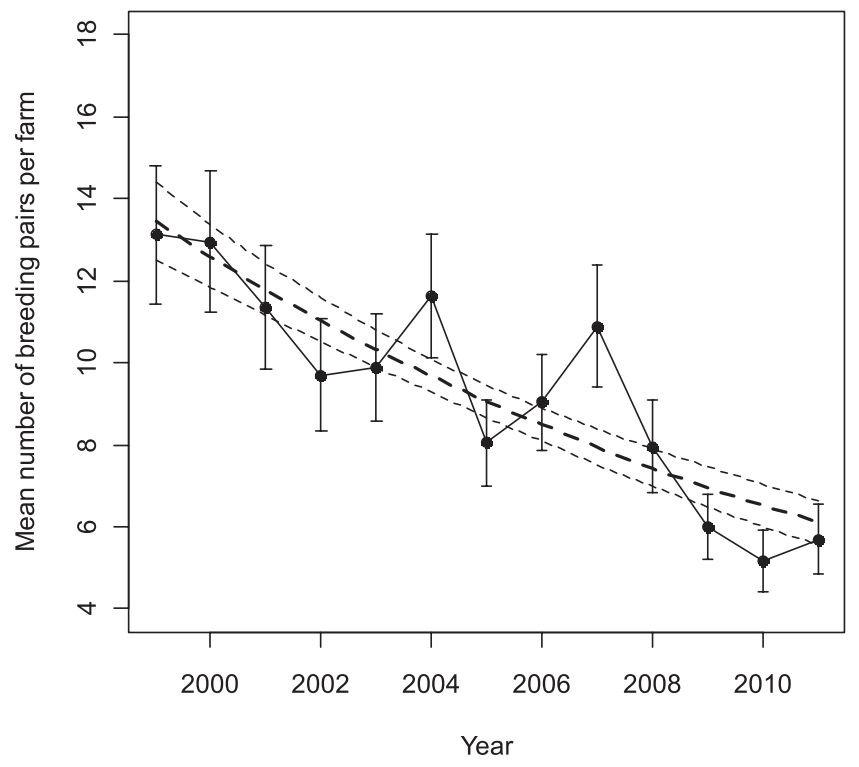

Figure 2. Mean number of breeding pairs per farm in the 87 farms monitored in all years in 1999-2011. Bars represent standard errors. Dashed lines represent population trend and its standard error estimated from a population growth model (see Methods).

During these years eight colonies went extinct and were not recolonised, two farms were colonised by one and two breeding pairs respectively, and two farms were colonised by a single pair in some years, but hosted no breeding pairs in 2011.

Mean hayfield extent $\mathrm{O}-200 \mathrm{~m}$ around the farms did not change significantly between 1999 and 2011 (estimate: $0.001 \pm 0.002$ proportion of hayfield $\times$ year $^{-1}, \mathrm{t}_{11}=0.338, P=0.742$, Figure 3 a) nor did that in the $200-400 \mathrm{~m}$ band change $\left(0.002 \pm 0.002\right.$ proportion of hayfield $\times$ year $^{-1}, \mathrm{t}_{11}=1.028$, $P=0.326$ ). Proportion of farms where livestock was reared declined significantly during the study period (estimate: $-0.038 \pm 0.018$ proportion of farms $\times$ year $^{-1}, z=-2.130, P=0.033$ ), from $75.9 \%$ in 1999 to $66.7 \%$ in 2011 (Figure 3 b).

\section{Hayfield distribution and number of breeding pairs per farm}

The model including hayfield extent $\mathrm{O}-200 \mathrm{~m}$ from the farm indicated a significant decline in colony size over time. In addition, the interaction between hayfield extent $\mathrm{o}-200 \mathrm{~m}$ and year was significant and positive (Table 1 ).

This significant interaction can be interpreted in two non-mutually exclusive ways. First, the effect of hayfield extent $\mathrm{o}-200 \mathrm{~m}$ from the farm on the number of breeding pairs has changed over time. Models run separately on data collected before and after 2005 (median year in the dataset; 2005 was excluded from the analyses) while excluding the hayfield extent by year interaction and the non significant livestock farming by year interaction, indicated that hayfield extent had no effect on colony size before $2005(z=-0.765, P=0.444)$, while it had a significant and positive effect after $2005(z=3.140, P=0.002)$.

Second, the rate of population decline differed between farms surrounded by different extent of hayfields. However, models run separately on farms having, on average, more or less than $50 \%$ of hayfields at $\mathrm{o}-200 \mathrm{~m}$ during the 13 years of the study indicated that the number of breeding pairs per farm declined significantly both in the former $(r=-0.049 \pm 0.015, z=-3.251, P=0.001, n=60$ farms $)$ and the latter group ( $r=-0.051 \pm 0.014, z=-3.515, P=0.001, n=27$ farms; other details not shown). 

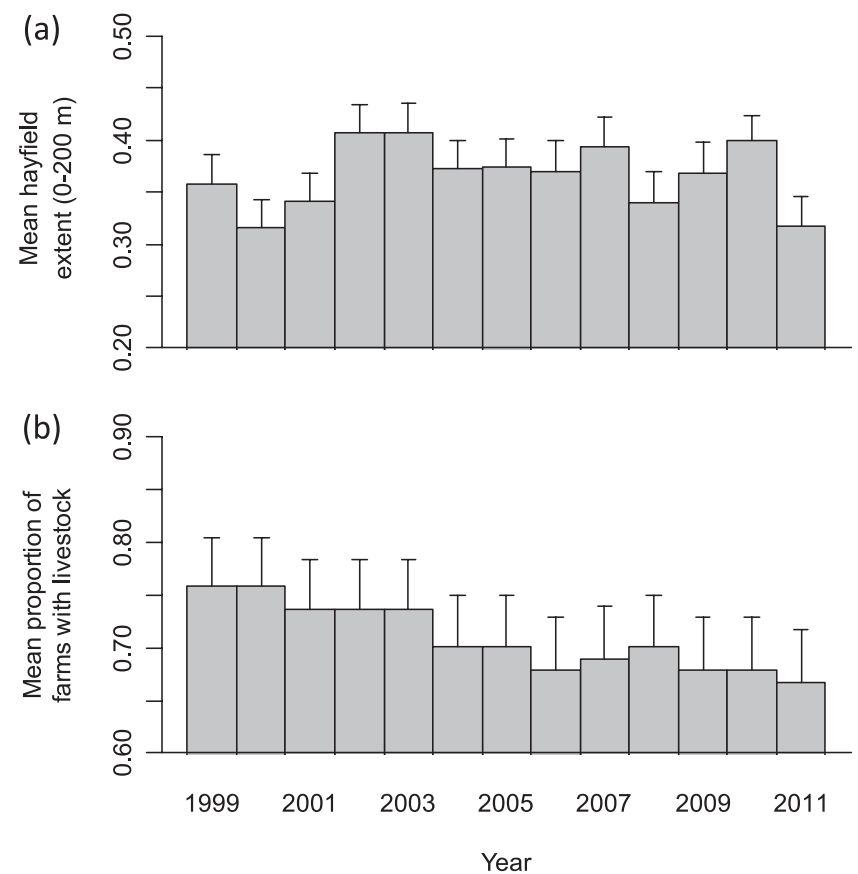

Figure 3. (a) Mean proportion of hayfields within $200 \mathrm{~m}$ from the colony and (b) proportion of farms with livestock at each year. Bars represent standard errors.

Colonies were also on average larger in farms with than without livestock, as indicated by the positive effect of livestock farming, but declined at a similar rate, as indicated by the non-significant interaction between livestock farming and year (Table 2). Finally, the negative interaction between livestock farming and hayfield extent suggested that hayfields differentially affected colony size according to presence or absence of livestock. In particular, the coefficients of the model (Table 2) indicated that the number of breeding pairs increased significantly with hayfield extent in farms without livestock $\left(0.378 \pm 0.131 \log (\right.$ pairs $) \times$ proportion of hayfields $\left.{ }^{-1}, z=2.877, P=0.004\right)$, while it was unaffected in farms with livestock $\left(0.002 \pm 0.066 \log (\right.$ pairs $) \times$ proportion hayfields $^{-1}, z=0.037$, $P=0.971$ ).

The model including hayfield extent $200-400 \mathrm{~m}$ only indicated that colony size declined significantly during time $(r=-0.065 \pm 0.010, z=-6.699 P<0.001)$, while all the other predictors

Table 1. Poisson GLMMs of the number of pairs per farm. Sample size is 87 farms and 13 years. All predictors were centred to their mean values before the analyses. $\varphi$ is the within-subject temporal-autocorrelation coefficient.

\begin{tabular}{lccrr}
\hline Effect & Coefficient & \multicolumn{1}{c}{ S.E. } & \multicolumn{1}{c}{$z$} & $P$ \\
\hline Intercept & 1.539 & 0.160 & 9.610 & $<0.001$ \\
Year & -0.055 & 0.011 & -4.944 & $<0.001$ \\
Livestock farming & 0.083 & 0.039 & 2.141 & 0.032 \\
Hayfield extent O-200 m & 0.112 & 0.065 & 1.710 & 0.087 \\
Livestock farming $\times$ Year & 0.013 & 0.015 & 0.914 & 0.360 \\
Hayfield extent O-200 m $\times$ Year & 0.042 & 0.014 & 2.926 & 0.003 \\
Hayfield extent O-200 m $\times$ Livestock farming & -0.376 & 0.137 & -2.747 & 0.006 \\
\hline
\end{tabular}

$\varphi=0.619$ 
Table 2. Gaussian LMMs of nestling phenotypic traits. Date is date at nestling measurement. All predictors were centred to their mean values before the analyses.

\begin{tabular}{|c|c|c|c|c|}
\hline Effect & Coefficient & S.E. & $z$ & $P$ \\
\hline \multicolumn{5}{|l|}{ Body mass } \\
\hline Intercept & $203 \cdot 582$ & 1.381 & $147 \cdot 356$ & $<0.001$ \\
\hline Date & 0.074 & 0.074 & 1.005 & 0.315 \\
\hline Nestling age & 6.796 & 1.663 & 4.088 & $<0.001$ \\
\hline Livestock farming & -4.898 & 3.813 & -1.284 & 0.199 \\
\hline Hayfield extent $\mathrm{o}-200 \mathrm{~m}$ & 5.600 & $5 \cdot 309$ & 1.055 & 0.291 \\
\hline Livestock farming $\times$ Date & -0.126 & 0.190 & -0.662 & 0.508 \\
\hline Hayfield extent $\mathrm{o}-200 \mathrm{~m} \times$ Date & 0.765 & 0.274 & 2.791 & 0.005 \\
\hline Hayfield extent $\mathrm{o}-200 \mathrm{~m} \times$ Livestock farm & -20.363 & 14.292 & -1.412 & 0.158 \\
\hline \multicolumn{5}{|l|}{ Tarsus length } \\
\hline Intercept & 110.864 & 0.322 & $344 \cdot 356$ & $<0.001$ \\
\hline Date & -0.094 & 0.014 & -6.639 & $<0.001$ \\
\hline Nestling age & 0.897 & 0.332 & 2.703 & 0.007 \\
\hline Livestock farming & 1.080 & 0.896 & 1.206 & 0.228 \\
\hline Hayfield extent $\mathrm{o}-200 \mathrm{~m}$ & -1.438 & 1.220 & -1.179 & 0.238 \\
\hline Livestock farming $\times$ Date & -0.016 & 0.038 & -0.416 & 0.677 \\
\hline Hayfield extent $\mathrm{o}-200 \mathrm{~m} \times$ Date & 0.100 & 0.051 & 1.952 & 0.051 \\
\hline Hayfield extent $\mathrm{o}-200 \mathrm{~m} \times$ Livestock farm & -4.776 & $3 \cdot 354$ & -1.424 & 0.154 \\
\hline \multicolumn{5}{|l|}{ Innermost rectrix length } \\
\hline Intercept & 172.183 & 3.027 & 56.881 & $<0.001$ \\
\hline Date & 0.630 & 0.164 & 3.838 & $<0.001$ \\
\hline Age & 27.081 & 3.633 & $7 \cdot 453$ & $<0.001$ \\
\hline Livestock farming & 11.550 & 8.531 & 1.354 & 0.176 \\
\hline Hayfield extent $\mathrm{o}-200 \mathrm{~m}$ & -5.476 & 11.502 & -0.476 & 0.634 \\
\hline Livestock farming $\times$ Date & -0.803 & 0.435 & -1.846 & 0.065 \\
\hline Hayfield extent $\mathrm{o}-200 \mathrm{~m} \times$ Date & 1.755 & 0.599 & 2.930 & 0.003 \\
\hline Hayfield extent $\mathrm{O}-200 \mathrm{~m} \times$ Livestock farm & -12.289 & 32.814 & -0.374 & 0.708 \\
\hline \multicolumn{5}{|l|}{ Immunocompetence index } \\
\hline Intercept & 150.347 & $5 \cdot 968$ & 25.193 & $<0.001$ \\
\hline Date & 1.156 & 0.179 & 6.456 & $<0.001$ \\
\hline Age & 2.905 & 2.607 & 1.114 & 0.265 \\
\hline Livestock farming & -9.189 & 14.330 & -0.641 & 0.521 \\
\hline Hayfield extent $\mathrm{o}-200 \mathrm{~m}$ & 32.150 & 22.935 & 1.402 & 0.161 \\
\hline Livestock farming $\times$ Date & -0.095 & 0.429 & -0.221 & 0.825 \\
\hline Hayfield extent $\mathrm{o}-200 \mathrm{~m} \times$ Date & 0.277 & 0.692 & 0.401 & 0.689 \\
\hline Hayfield extent $\mathrm{o}-200 \mathrm{~m} \times$ Livestock farm & 47.655 & 38.348 & -1.243 & 0.214 \\
\hline
\end{tabular}

were not significant $(|z| \leq 1.321, P \geq 0.186$; other details not shown). These results therefore suggest that hayfield extent $\mathrm{O}-200 \mathrm{~m}$ from the farm, but not 200-400 m, affected colony size.

The model investigating the extent to which variation in hayfields and livestock influenced colony size indicated that colony size changed according to the combined effect of these predictors (effect of the interaction between livestock farming and hayfield extent: $-0.497 \pm 0.175 \log$ (pairs) $\times$ proportion hayfields $\left.{ }^{-1}, z=-2.844, P=0.004\right)$. The main terms of livestock farming and hayfield extent had nonsignificant effects (difference in colony size between farms with and without livestock: $0.159 \pm 0.087$ $\log$ (pairs), $z=1.990, P=0.067$; effect of hayfield extent: $0.067 \pm 0.078 \log ($ pairs $) \times$ proportion of hayfields ${ }^{-1}, z=0.864, P=0.388$ ). The coefficients from this model allowed us to calculate that the reduction in the number of farms where livestock was reared (see above) may have determined a decline of about 1.64\% in the Barn Swallow population between 1999 and 2011, corresponding to $2.9 \%$ of the general decline (56.6\%, see above) observed in the population during the same years. Hayfield extent $\mathrm{o}-200 \mathrm{~m}$ from the farms did not change over time (Figure 3, see also above), and 
therefore changes in agricultural practices should have not contributed to the observed decline. However, a future increase in the average extent of hayfields around the farms from the current $36.6 \%$ to $53.3 \%$ would determine an increase in the Barn Swallow population equal to the reduction in the number of breeding pairs due to cessation of livestock farming.

\section{Clutch size, hatching date and number of fledged offspring}

Mean size of first clutches declined significantly with mean hatching date $(-0.013 \pm 0.002$ eggs day $^{-1}, z=-6.978, P<0.001, n=804$ mean within-farm and year clutch sizes). Year, livestock farming, hayfield extent $0-200 \mathrm{~m}$, number of breeding pairs and the interactions between year and the other variables had no significant effects on mean clutch size $(|z| \leq 1.575, P \geq 0.115$ in all cases). Mean hatching date of clutches advanced significantly in recent years $\left(-0.433 \pm 0.102\right.$ days $\times$ year $^{-1}$, $z=-4.250, P<0.001, n=827$ mean within-farm and year hatching dates), but at a slower rate in farms with than without livestock (effect of the interaction between livestock farming and year: $z=1.971, P=0.049$; advancement rate in farms with livestock: $-0.284 \pm 0.109$ days $\times$ year $^{-1}$; in farms without livestock: $-0.796 \pm 0.233$ days $\times$ year $^{-1}$ ). Hatching date also advanced in farms with large hayfields within $200 \mathrm{~m}\left(-3.045\right.$ days $\times$ proportion of hayfields $\left.{ }^{-1}, z=-2.178, P=0.029\right)$. No other variable or interaction significantly predicted mean hatching date $(|z| \leq 1.805, P \geq 0.071)$. Mean brood size declined significantly with hatching date $\left(-0.015 \pm 0.005\right.$ nestlings $\times$ day $^{-1}$, $z=-2.815, P=0.005, n=788$ mean within-farm and year brood sizes). No other significant effect was observed $(|z| \leq 1.711, P \geq 0.087)$. A further analysis indicated that hayfield extent did not affect mean brood size either per se or in interaction with other predictors, even when hatching date was removed from the model $(|z| \leq 0.940, P \geq 0.347$; other details not shown).

\section{Nestling quality}

Nestling body mass and feather development were significantly predicted by hayfield extent o-200 $\mathrm{m}$ from the colony and in both cases the effect of hayfield extent changed during the breeding season, as indicated by the significant hayfield extent by date interaction (Table 2). Tarsus length showed a marginally non-significant tendency towards a similar pattern of variation with date, while cell-mediated immunity was unaffected by hayfield extent either per se or in interaction with other variables (Table 2 ).

To better interpret these results we re-fitted the models of body mass and rectrix length by entering date as a dichotomous variable indicating whether a given nest was measured before or after the median date at measure of all nests in the sample (4 June). These models indicated that body mass did not change with hayfield extent in early nests $(-8.711 \pm 6.468 \mathrm{~g} \times 10 \times$ proportion of hayfields ${ }^{-1}, z=-1.345, P=0.178$ ), while it increased in late nests (17.111 $\pm 7.911 \mathrm{~g} \times 1 \mathrm{o} \times$ proportion of hayfields ${ }^{-1}, z=2.162, P=0.031$; Figure 4 a).

On the other hand, innermost rectrix length showed a weak and non-significant trend to decrease with hayfield extent in early nests $\left(-35.438 \pm 19.334 \mathrm{~mm} \times 10 \times\right.$ proportion of hayfields ${ }^{-1}, z=-1.833$, $P=0.067)$, and to increase in late nests $\left(18.192 \pm 13.572 \mathrm{~mm} \times 10 \times\right.$ proportion of hayfields ${ }^{-1}$, $z=-1.340, P=0.180$, Figure 4 b). Cell-mediated immunity increased significantly during the breeding season, while body mass as well as tarsus and rectrix length increased with nestling age (Table 2).

\section{Discussion}

Our study population of Barn Swallows suffered a dramatic decline of more than $50 \%$ between 1999 and 2011 , corresponding to an annual decrease of $6.6 \%$. This decline rate is almost identical to that estimated by Ambrosini et al. (2012) in a recent paper based on data collected in the same study area between 1999 and 2010 (6.3\% per year) to which we refer for a discussion of demographic trends in different geographical areas. Here we only emphasize that this decline is much steeper than that observed over the whole of Europe (I\% per year; EBCC 2008, PECBMS 2009). 

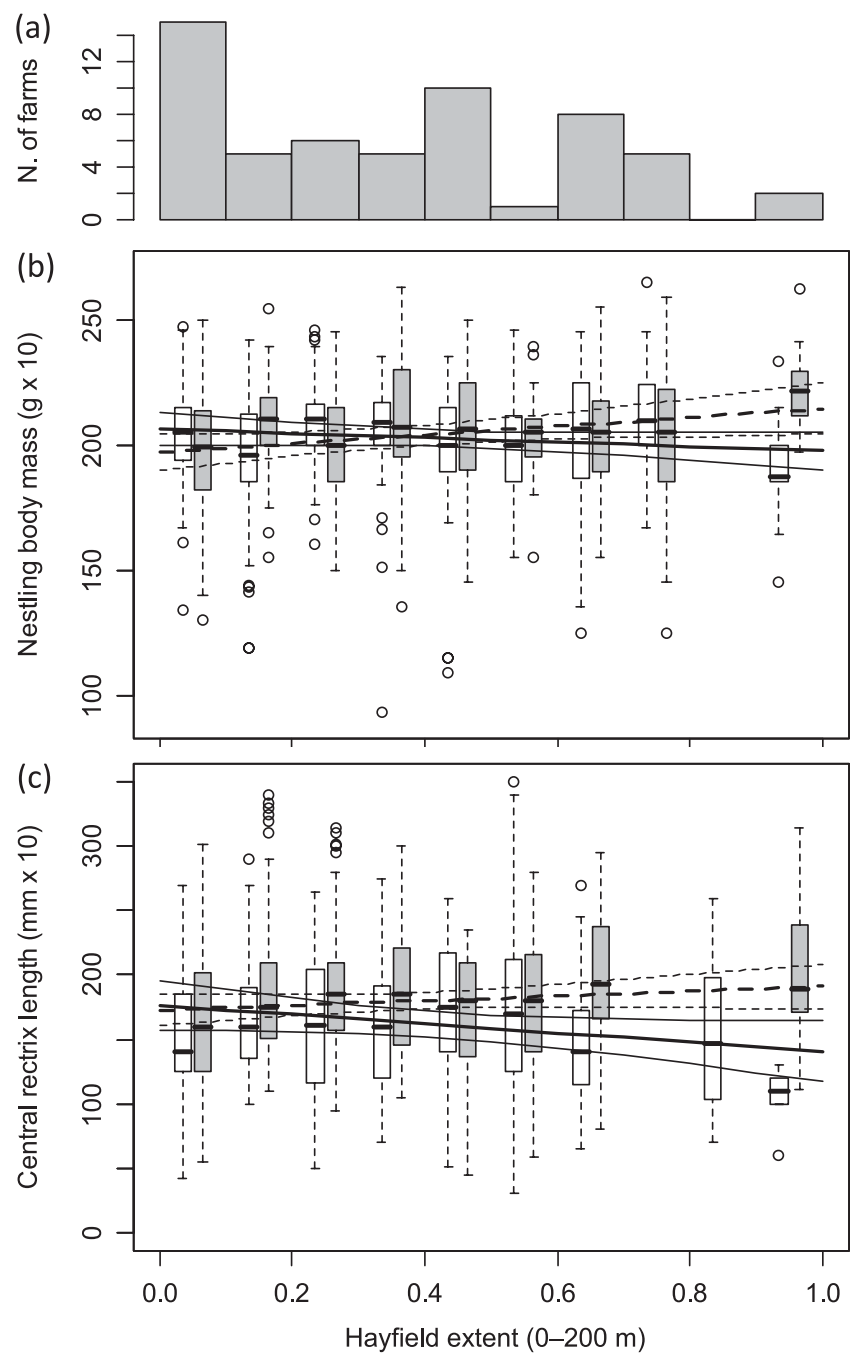

Figure 4. (a) Frequency distribution of farms with a given average proportion of hayfields within $200 \mathrm{~m}$ from the colony in 2001, (b) body mass and (c) innermost rectrix length of Barn Swallow nestlings in farms with different proportion of hayfields within $200 \mathrm{~m}$ from the colony before (open boxes and dashed lines) and after (filled boxes and solid lines) the median date at nestling measure ( $65=4$ June). Boxes are drawn separately for nestlings measured before or after 4 June within o.I intervals of hayfields extent around farms, and slightly shifted from the median value within interval. Lines are drawn according to the coefficients of models in Table 2.

The decline of individual colonies occurred at rates that were not related to environmental features of breeding sites. Indeed, demographic trends did not differ in farms with and without livestock, and in farms having on average more or less than $50 \%$ hayfields within $200 \mathrm{~m}$, as clearly indicated by the analyses run separately on these two categories of farms. However, presence of livestock and hayfield extent within $200 \mathrm{~m}$ from the farm influenced colony size, and their relative importance has changed over time. Indeed, presence of livestock positively influenced colony size in all years, while hayfield extent within $200 \mathrm{~m}$ positively influenced colony size in recent years but not in the past. In addition, in all years, hayfield extent positively affected colony size on farms without 
livestock, but not on farms with livestock. Conversely, hayfield extent within $200-400 \mathrm{~m}$ from the colonies had no significant effect on colony size.

Hayfields surrounding farms are the favourite foraging habitat of this species (Ambrosini et al. 2002, Evans et al. 2007), and therefore a positive effect of the extent of hayfields on Barn Swallow abundance is not surprising. Hayfields may offer a larger availability of prey or better quality of prey than other crops (Evans et al. 2007). Importantly, hayfields close to breeding farms may represent a more important source of food than those located few hundred meters away (Ambrosini et al. 2002), because they may reduce the energetic cost of foraging.

The positive association between livestock farming and colony size is well documented in the same study area (Ambrosini et al. 2002) and in other parts of Europe (Møller 2001, Turner 2006), and cessation of livestock farming usually leads to an abrupt decline in colony size (Møller 2001, Ambrosini et al. 2012). This was well documented in a recent paper based on data collected in the same, as well as other, study areas in Northern Italy in which colony sizes observed in 2010 were compared to those observed in the same farms in 2001, and variation in colony size was related to change in farming practices between 2001 and 2010, but not to variation in crop extent around farms, since this information was not available for all study areas (Ambrosini et al. 2012). The present paper, though restricted to a smaller study area, presents a more detailed investigation of the ecological variables potentially affecting demographic trends of Barn Swallow colonies, as it is based on annual censuses, and therefore year-to-year variation in colony size could be modelled on a continuum according to year-to-year variation both in farming practices and hayfield extent. In addition, by investigating the concomitant effects of hayfield extent and livestock farming on breeding success and nestling phenotype, this study provides insights into the potential mechanisms through which ecological features of breeding sites may benefit Barn Swallows.

The analyses showed that colony size increased with the extent of hayfields within $200 \mathrm{~m}$ on farms where livestock is not reared, while it was unaffected by hayfield extent on farms with livestock. Presence of livestock may determine abundance of flying insects at a farm, independently from the extent of hayfields in the surroundings, while large hayfields close to the colony may be an important source of food for Barn Swallows breeding in farms without livestock.

The significant interaction between the extent of hayfields within $200 \mathrm{~m}$ from the colony and year suggests that the effect of hayfields has changed during the 13 years of the study, as also indicated by the analyses run separately on years before and after 2005. In particular, colony size increased with hayfield extent after 2005, but not before. The importance of wide hayfields close to the colony seems therefore to have increased in recent years, concomitantly with the reduction in the number of farms with livestock in the study area.

To elucidate the possible mechanisms linking hayfield extent and colony size we first investigated the variation in mean within colony clutch or brood size, and hatching date recorded in all years between 1999 and 2011 . Indeed, farms where conditions for reproduction are better, may attract a larger number of first-year breeders, which disperse from the natal colony and usually represent the large majority of individuals at a farm (Saino et al. 2012). We observed that mean hatching date advanced significantly during the study period, consistently with the advancement in breeding date of Barn Swallows recorded in another area of Northern Italy (Rubolini et al. 2007). However, hatching date advanced by c.9.5 days in farms without livestock in 1999-2011, but only by c.3.5 days in farms with livestock. In addition, we found that mean hatching date advanced more in farms surrounded by large hayfields. An advancement in mean hatching date may be explained by changes in the proportion of young and old individuals in the population. Indeed, cessation of livestock farming likely determines a decline in colony size via a lower recruitment of young individuals (Møller 2001). Young swallows at their first breeding attempt usually arrive and breed c.20 days later than older individuals (Saino et al. 2004). If young birds are recruited in smaller numbers after cessation of livestock farming, the proportion of old early-breeding individuals at a colony should increase, and mean reproductive date advance. Conversely, the advance in breeding date with increasing extent of hayfields is probably due to earlier breeding by all individuals, irrespective of age. Indeed, the proportion of late-breeding, 
young individuals should not decrease in farms surrounded by large hayfields, as suggested by the fact that colony size does not decrease with hayfield extent. Alternatively, old individuals may occur at a greater proportion in farms surrounded by large hayfields because, having bred under favourable conditions, they may achieve higher survival rates.

When we investigated variation in phenotypic traits of nestlings, we observed a significant effect of hayfield extent on body mass and feather development. In particular, we found that both nestling body mass and plumage development increased with increasing extent of hayfields within $200 \mathrm{~m}$ from the colony in late but not in early broods, implying that large hayfields around the colony enhance the quality of offspring reared late in the breeding season. The same patterns could also be observed in tarsus length, although in this latter case the effect was marginally non significant. In addition, the proportion of male nestlings in a brood increased with the extent of hayfields within $200 \mathrm{~m}$ from the colonies (Romano et al. 2012), but not at larger distance (A. Romano pers. comm.).

Body mass and feather length positively predicted survival prospects of Barn Swallow nestlings (Turner 2006, Grüebler and Naef-Daenzer 2010). Large hayfields within $200 \mathrm{~m}$ from the colony may therefore enhance survival prospects of the offspring that hatched late in the season. Late hatched offspring, in turn, are usually produced by individuals at their first breeding attempt, which usually breed later than older individuals (Møller 1994, Turner 2006). First-year breeders may therefore base the choice of their breeding site according to hayfield extent around farms, as their offspring may benefit most by being reared on farms surrounded by large hayfields.

The offspring usually contribute only marginally to the population trend of their natal colony, as Barn Swallows rarely return to breed at the same farm where they hatched, and local recruitment rate is only about $5 \%$ and is strongly biased toward males (Møller 1994, Turner 2006). However, the concomitant effects of a general better quality of the nestlings (the present study), which enhances survival prospects, and a larger proportion of male nestlings (Romano et al. 2012), which are more philopatric than females, may determine a larger number of local recruits in farms surrounded by large hayfields. Since average longevity of Barn Swallows is about two years (Møller 1994, Turner 2006) and one-year-old individuals always represent c.60\% of the birds in a colony (Saino et al. 2012), a larger recruitment rate of young individuals, both hatched in the same farms and in others, to the breeding colony may therefore be the mechanism determining the larger size of colonies surrounded by wide hayfields.

\section{Conservation implications}

The novel insights provided by the present study on the relationships linking the size of Barn Swallow colonies and the ecological features of breeding sites may have implications for the conservation of this declining species. Although the ecological variables we considered explained only a small fraction (2.9\%) of the decline of the population, suggesting that ecological conditions faced by Barn Swallows during migration and wintering may be crucial in affecting population trends, we suggest some simple conservation actions that may contribute to reduce the decline of breeding colonies. Since colonies are larger in farms with livestock, maintenance of livestock farming is probably the best strategy available at the breeding quarters to buffer the decline of colonies. However, conservation actions aimed at maintaining livestock farming on farms are difficult to implement over wide geographical scales, as several farms cease livestock farming each year because of low profitability. Nevertheless, enlargement of hayfields around farms where livestock farming ceases may buffer the decline of local colonies. Conservation actions aimed at increasing the extent of hayfields around farms would have a lower cost than those aiming to maintain livestock farming, because it would be equal to the difference in income for the farmers between hayfields and maize fields, which usually replace hayfields when livestock farming ceases. Indeed, in this area, maize fields currently provide higher income to farmers than hayfields (authors' unpubl. data).

An even cheaper strategy to buffer colony decline of Barn Swallows would be to simply modify the position of crops around the same farm, setting hayfields preferentially close to farms, and maize fields and other crop types at larger distances. Since only hayfield extent within $200 \mathrm{~m}$ from the 
colony affects population trend, such a strategy would benefit Barn Swallows, even if the total amount of hayfields in the study area did not change. Hopefully, these strategies may contribute to reduce the sharp decline in this flagship species of agricultural habitats.

\section{Acknowledgements}

We are grateful to all the farm owners that allowed us to census Barn Swallows in their houses and cowsheds for 13 years, to the administration of the Parco Regionale Adda Sud for logistic support and to all the students that contributed to field work. The Parco Regionale Adda Sud, the Regione Lombardia and the Parco Pineta di Appiano Gentile e Tradate financially supported the long-term monitoring project of Barn Swallows in different years. We thank Dan Chamberlain for his valuable comments on a previous version of the manuscript.

\section{References}

Ambrosini, R. and Saino, N. (2010) Environmental effects at two nested spatial scales on habitat choice and breeding performance of barn swallow. Evol. Ecol. 24: 491-508.

Ambrosini, R., Bolzern, A. M., Canova, L., Arieni, S., Møller, A. P. and Saino, N. (2002) The distribution and colony size of barn swallows in relation to agricultural land use. J. Appl. Ecol. 39: 524-534.

Ambrosini, R., Ferrari, R. P., Martinelli, R., Romano, M. and Saino, N. (2006) Seasonal, meteorological, and microhabitat effects on breeding success and offspring phenotype in the barn swallow, Hirundo rustica. Ecosci. 13: 298-307.

Ambrosini, R., Rubolini, D., Trovò, P., Liberini, G., Bandini, M., Romano, A., Sicurella, B., Scandolara, C., Romano, M. and Saino, N. (2012) Maintenance of livestock farming may buffer population decline of the Barn Swallow Hirundo rustica. Bird Conserv. Internatn. 22: $411-428$.

BirdLife International (2004) Birds in Europe: Population estimates, trends and conservation status. Cambridge, UK: BirdLife International.

Both, C., Van Turnhout, C. A. M., Bijlsma, R. G., Siepel, H., Van Strien, A. J. and Foppen, R. P. B. (2010) Avian population consequences of climate change are most severe for longdistance migrants in seasonal habitats. Proc. R. Soc. B. 277: 1259-1266.

Christe, P., de Lope, F., Gonzalez, G., Saino, N. and Møller, A. P. (2001) The influence of environmental conditions on immune responses, morphology and recapture probability of nestling house martins (Delichon urbica). Oecologia 126: 333-338.
Donald, P. F., Green, R. E. and Heath, M. F. (2001) Agricultural intensification and the collapse of Europe's farmland bird populations. Proc. R. Soc. B 268: 25-29.

Donald, P. F., Sanderson, F. J., Burfield, I. J. and van Bommel, F. P. J. (2006) Further evidence of continent-wide impacts of agricultural intensification on European farmland birds, 1990-2000. Agricult. Ecosyst. Environ. 116: 189-196.

EBCC (2008) Trends of common birds in Europe, 2008 update. European Bird Census Council. Available at: http://www.ebcc.info/index. php? ID $=358$.

Engen, S., Sæther, B. and Møller, A. P. (2001) Stochastic population dynamics and time to extinction of a declining population of barn swallows. J. Anim. Ecol. 70: 789-797.

Evans, K. L., Wilson, J. D. and Bradbury, R. B. (2003) Swallow Hirundo rustica population trends in England: data from repeated historical surveys. Bird Study 50: 178-181.

Evans, K. L., Wilson, J. D. and Bradbury, R. D. (2007) Effects of crop type and aerial invertebrate abundance on foraging barn swallows Hirundo rustica. Agricult. Ecosyst. Environ. 122: $267-273$.

Gaston, K. J., Blackburn, T. M. and Klein Goldewijk, K. (2003) Habitat conversion and global avian biodiversity loss. Proc. R. Soc. B 270: 1239-1300.

Grüebler, M. U. and Naef-Daenzer, B. (2010) Fitness consequence of timing of breeding in birds: date effects in the course of a reproductive episode. J. Avian. Biol. 41: 282-291.

Grüebler, M. U., Korner-Nievergelt, F. and von Hirschheydt, J. (2010) The reproductive 
benefits of livestock farming in barn swallows Hirundo rustica: quality of nest site or foraging habitat? J. Appl. Ecol. 47: 1340-1347.

Murphy, M. (2003) Avian population trends within the evolving agricultural landscape of Eastern and Central United States. The Auk 120: 20-34.

Møller, A. P. (1994) Sexual selection and the Barn Swallow. Oxford, UK: Oxford University Press.

Møller, A. P. (2001) The effect of dairy farming on barn swallow Hirundo rustica abundance, distribution and reproduction. J. Appl. Ecol. 38: 378-389.

Møller, A. P. and Saino, N. (2004) Immune response and survival. Oikos 104: 299-304.

Orłowski, G. and Karg, J. (2011) Diet of nestling Barn Swallows Hirundo rustica in rural areas of Poland. Cent. Eur. J. Biol. 6: 1023-1035.

PECBMS (2009) The state of Europe's common birds 2008. Czech Republic: CSO/RSPB.

R Development Core Team (2008) R: A language and environment for statistical computing. Vienna, Austria: R Foundation for Statistical Computing.

Robinson, R. A., Crick, H. Q. P. and Peach, W. (2003) Population trends of Swallows Hirundo rustica breeding in Britain. Bird Study 50: 1-7.

Romano, A., Ambrosini, R., Caprioli, M., Bonisoli-Alquati, A. and Saino, N. (2012) Secondary sex ratio covaries with demographic trends and ecological conditions in the barn swallow. Evol. Ecol. 26: 1041-1053.

Rubolini, D., Ambrosini, R., Caffi, M., Brichetti, P., Armiraglio, S. and Saino, N. (2007) Long-term trends in first arrival and first egg laying dates of some migrant and resident bird species in northern Italy. Int. J. Biometeorol. 51: 553-563.

Saino, N., Ambrosini, R., Rubolini, D., von Hardenberg, J., Provenzale, A., Hüppop, K., Hüppop, O., Lehikoinen, A., Lehikoinen, E., Rainio, K., Romano, M. and Sokolov, L. (2011) Climate warming, ecological mismatch at arrival and population decline in migratory birds. Proc. R. Soc. B 278: 835-842.

Saino, N., Calza, S. and Møller, A. P. (1997) Immunocompetence of nestling barn swallows in relation to brood size and parental effort. J. Anim. Ecol. 66: 827-836.
Saino, N., Romano, M., Ambrosini, R., Rubolini, D., Boncoraglio, G., Caprioli, M. and Romano, A. (2012) Longevity and lifetime reproductive success of barn swallow are predicted by their hatching date and phenotypic quality. J. Anim. Ecol. 81: 1004-1012.

Saino, N., Szép, T., Romano, M., Rubolini, D., Spina, F. and Møller, A. P. (2004) Ecological conditions during winter predict arrival date at the breeding quarters in a trans-Saharan migratory bird. Ecol. Lett. 7: 21-25.

Sanderson, F. J., Donald, P. F., Pain, D. J., Burfield, I. J. and van Bommel, F. P. J. (2006) Long-term population declines in AfroPalearctic migrant birds. Biol. Conserv. 131: 93-105.

Schielzeth, H. and Forstmeier, W. (2009) Conclusions beyond support: overconfident estimates in mixed models. Behav. Ecol. 20: 416-420.

Siriwardena, G. M., Baillie, S. R. and Wilson, J. (1998) Variation in the survival rates of some British passerines with respect to their population trends on farmland. Bird Study 45: 276-292.

Smits, J. E., Bortolotti, G. R. and Tella, J. L. (1999) Simplifying the phytohaemagglutinin skin-testing technique in studies of avian immunocompetence. Funct. Ecol. 13: 567-572.

Spina, F. (1998) The EURING swallow project: a large-scale approach to the study and conservation of a long-distance migrant. Pp. 151-162. in J. Leshem, E. Lachman and P. Berthold, eds. Migrating birds know no boundaries. Proceedings of the international symposium. Israel: The Torgos 28.

Thomas, C. D., Cameron, A., Green, R. E., Bakkenes, M., Beaumont, L. J., Collingham, Y. C., Erasmus, B. F. N., De Siqueira, M. F., Grainger, A., Hannah, L., Hughes, L., Huntley, B., Van Jaarsveld, A. S., Midgley, G. F., Miles, L., Ortega-Huerta, M. A., Peterson, A. T., Phillips, O. L. and Williams, S. E. (2004) Extinction risk from climate change. Nature 427: $145-148$.

Turner, A. (2006) The Barn Swallow. Berkhamstead, UK: T and A D Poyser.

Zwarts, L., Bijlsma, R. G., van der Kamp, J. and Wymenga, E. (2009) Living on the edge. Wetlands and birds in a changing Sahel. Utrecht, The Netherlands: KNNV Publishing. 
BEATRICE SICURELLA, ROBERTO AMBROSINI*

Dipartimento di Biotecnologie e Bioscienze, Università degli Studi di Milano-Bicocca, p.zza della Scienza 2, 20126 Milan, Italy.

\section{MANUELA CAPRIOLI, ANDREA ROMANO, MARIA ROMANO, DIEGO RUBOLINI,}

NICOLA SAINO

Dipartimento di Bioscienze, Università degli Studi di Milano, via Celoria 26, 20133 Milan, Italy.

*Author for correspondence: email: roberto.ambrosini@unimib.it

Received 22 June 2012; revision accepted 9 October 2012;

Published online 3 June 2013 